\title{
Involvement of Membrane Blebbing in Immunological Disorders and Cancer
}

\author{
Maitham A. Khajah ${ }^{a}$ Yunus A. Luqmani ${ }^{b}$ \\ Departments of a Pharmacology and Therapeutics and bPharmaceutical Chemistry, Faculty of Pharmacy, \\ Kuwait University, Safat, Kuwait
}

\section{Key Words}

Bleb - Actin · Motility · Invasion - Endocrine resistance ·

Breast cancer

\begin{abstract}
Cellular blebbing is a unique form of dynamic protrusion emanating from the plasma membrane which can be either apoptotic or nonapoptotic in nature. Blebs have been observed in a wide variety of cell types and in response to multiple mechanical and chemical stimuli. They have been linked to various physiological and pathological processes including tumor motility and invasion, as well as to various immunological disorders. They can form and retract extremely rapidly in seconds or minutes, or slowly over hours or days. This review focuses on recent evidence regarding the role of blebbing in cell locomotion with particular emphasis on its role in tumor metastasis, indicating the role of specific causative molecules. The phenomenon of blebbing has been observed in endocrine-resistant breast cancer cells in response to brief exposure to extracellular alkaline $\mathrm{pH}$, which leads to enhanced invasive capacity. Genetic or pharmacological targeting of cellular blebs could serve as a potential therapeutic option to control tumor metastasis.
\end{abstract}

(c) 2015 S. Karger AG, Basel

\section{Introduction}

Cellular blebbing, first described in 1919 [1] as hyaline blisters or bubbles, was later characterized as smooth circular extensions $(2-15 \mu \mathrm{m}$ in diameter) of the plasma membrane that expand from the cytoplasm and retract to the initial site of origin [2]. These protrusions have received more attention in recent years due to their occurrence in widely differing cell types and their association with various physiological and pathological conditions [3-5]. This review discusses the role of the actin machinery in bleb formation, the various cell types which produce these protrusions, the heterogeneous stimuli of blebbing and its role in various functions including locomotion. In addition, recent data demonstrating the role of alkaline $\mathrm{pH}$ as a novel stimulus of blebbing, specifically in endocrine-resistant breast cancer cells, and its association with cell motility are discussed.

Blebs have been observed in numerous cell types including fibroblasts [6], endothelial and mesenchymal cells [4], cancer cells [7-11], immune cells [12-14], germ cells [15-17], ameba [18], parasites [19] and bacteria [20-22]. It was originally assumed that blebbing was related solely to pathological conditions in response to nonspecific cellular insults such as lipid peroxidation [23], anoxia [24]

\begin{tabular}{ll}
\hline KARGER & $\begin{array}{l}\text { @ 2015 S. Karger AG, Basel } \\
1011-7571 / 15 / 0258-0018 \$ 39.50 / 0 \quad \text { Openger }\end{array}$ \\
E-Mail karger@karger.com & $\begin{array}{l}\text { Thisis an Open Access article licensed under the terms of the } \\
\text { Creative Commons Attribution-NonCommercial 3.0 Un- } \\
\text { www.karger.com/mpp }\end{array}$ \\
$\begin{array}{l}\text { ported license (CC BY-NC) (www.karger.com/OA-license), } \\
\text { applicable to the online version of the article only. Distribu- } \\
\text { tion permitted for non-commercial purposes only. }\end{array}$
\end{tabular}

Yunus A. Luqmani

Department of Pharmaceutical Chemistry

Faculty of Pharmacy, Kuwait University

PO Box 24923, Safat 13110 (Kuwait)

E-Mail Yunus@hsc.edu.kw 

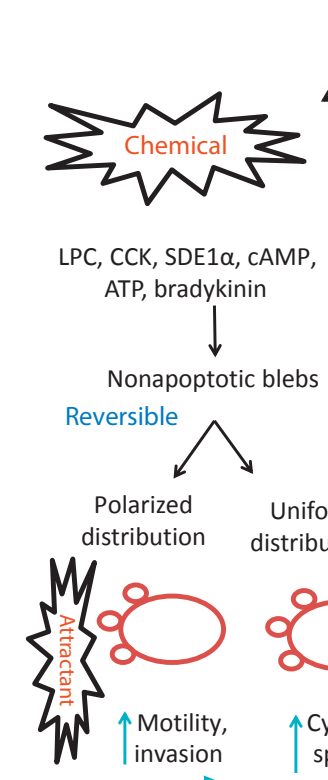

s/3.

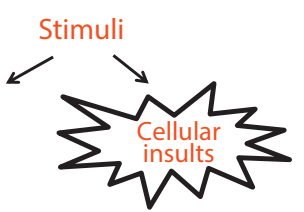

Lipid peroxidation, anoxia, energy depletion
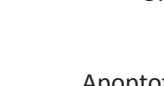

Apoptotic blebs uniformly distributed uniformly
Irreversible

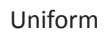
distribution
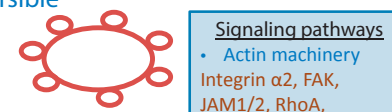
Actin machinery Integrin a2, FAK, JAM1/2, RhoA, CDC42, formins,

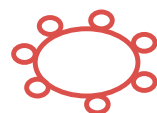

Cytokinesis,

spreading, mitosis

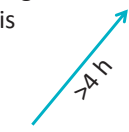

ER-ve breast cancer cells exposed to alkaline $\mathrm{pH}$
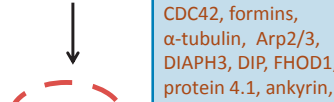
protein 4.1, ankyrin,
tropomyosin, ezrin tropomodulin, ROCK, Cell lysis Rac, filamin, talin, PIP2

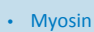
- Myosin MLCK - Aquaproteins AQP9

Fig. 1. Various stimuli and molecules involved in the formation of apoptotic and nonapoptotic blebs. Cellular blebbing can be induced in response to various mechanical and chemical stimuli and leads to the activation of several downstream signaling molecules depending on the stimuli and cell type. These protrusions have been shown to play an important role in various physiological and pathophysiological conditions, such as immune-related conditions and cancer pathogenesis, as discussed in the text. Apoptotic cells exhibit uniform blebbing that eventually results in cell lysis, whereas nonapoptotic blebs are reversible and involved in motile functions necessary for directional cellular migration. In the case of endocrine-resistant cancer cells, a high external $\mathrm{pH}$ can induce either condition depending upon the time of exposure. The panel on the right lists the molecules that have been implicated in bleb formation.

and energy depletion [24-26], with motility/invasion [11, 27] and multidrug resistance in tumor cells [28], or as a prerequisite for necrosis. However, it is now considered to be an important physiological process which occurs during cell blastulation in Fundulus deep cells [29], cytokinesis, cell spreading, virus infection, protective mechanisms against injury (either physical or chemical stress) [30-32] and as a hallmark of the execution stage of apoptosis [33]. For example, rabbit renal proximal epithelial cells form extensive blebs after hypoxic injury [34].

Blebbing and Cell Motility
It had been suggested that bleb formation occurs at a rate faster than that of actin filament elongation and polymerization needed for the formation of other types of cellular protrusions such as lamellipodia [35-37]. It can be either reversible (nonapoptotic) or irreversible (apoptotic). Nonapoptotic blebbing has been seen in various cellular processes including mitosis $[6,9,38]$, spreading $[4,9,39-41]$ and migration $[5,16,42,43]$, as well as after trypsin-mediated detachment of cultured cells [3, 39]. The apoptotic form of blebbing was detected by the treatment of serum-starved cells with the caspase inhibitor Z-VAD-FMK, which enables apoptotic cells to bleb for variable periods stretching from hours to days; depolymerization of actin inhibits this phenomenon [44]. The distribution profile of newly formed blebs appears to be correlated with particular cellular processes. During cell motility, they are polarized towards the source of a stimulus, while during apoptosis/necrosis they are uniformly distributed around the entire cell surface (fig. 1). The time scale of bleb formation varies considerably. Apoptotic blebs take 24-48 h, whereas alkaline-challenged estrogen receptor (ER)-depleted breast cancer cells exhibit them in 5-10 min [11], and Dictyostelium cells form them in just $1 \mathrm{~s}$ [45]. In some cases, the total cell volume is preserved during blebbing [46], but in others it is significantly reduced $[11,27]$.

The bleb life cycle can be subdivided into three phases: (1) nucleation, (2) expansion (cytosol flowing from the cell body into the bleb [9]) and (3) retraction (driven by myosin [7]). They are formed when the plasma membrane separates from the underlying actin cortex and is pushed outwards by fluid pressure [31] exerted by contraction of the cell cortex. This leaves little F-actin beneath the bleb membrane as it expands. Various mechanisms have been suggested for the generation of these protrusions, including actin filament elongation [47-49], hydrostatic pressure generated by cortical contractions giving rise to pseudopod formation $[50,51]$, gel-swelling pressure involving osmotic expansion [52], lipid or membrane flow involving endocytosis-/exocytosis-mediated recycling of membrane components [53] or cell substratum adhesiveness [54]. However, other models have suggested that their formation and extension occur as a result of an osmotic flux followed by actin polymerization [55]. Reducing intracellular hydrostatic pressure by placing cells in hypertonic media inhibits bleb and lamellipodia formation, locomotion and polarity $[51,56]$. Fedier and Keller [57] showed that reducing free water content inside Walker carcinoma cells by $39 \%$ inhibited bleb formation and locomotion. This leads to reduced intracellular 
hydrostatic pressure, increased viscoelastic resistance to passive and swelling deformation and decreased space between cytoplasmic components, without a significant increase in viscosity of the aqueous phase or any change in the amount of F-actin. Pseudopod-like blebs were also seen in U937 monocytes stimulated by permeabilization of the cellular membrane with a nanosecond-pulsed electric field; this was inhibited by partial isosmotic replacement of extracellular sodium chloride for a larger solute such as sucrose, suggesting that colloid-osmotic water uptake is the driving force for bleb formation. Pretreatment with the actin depolymerizer cytochalasin D prevented membrane blebbing, underlining the requirement of the actin cytoskeleton [58].

Other evidence has also suggested a role for aquaprotein (AQP) channels in bleb formation. The AQPs are membrane-anchored channels $[59,60]$ defined by their permeability characteristics in water and solutes like glycerol [61]. They have been proposed to play a role in cell migration, due to their polarization towards the leading edge of migrating neutrophils [13, 62-64]. Overexpression of AQP9 in HEK-293 cells resulted in a rapid influx of water and increased intracellular pressure, leading to the formation of filopodia bleb-like protrusions, contributing to their motile behavior [65].

\section{Role of the Actin Machinery}

The contractile cortex is a layer of cytoskeleton $(50 \mathrm{~nm}$ to $2 \mu \mathrm{m}$ thick) under the plasma membrane that is rich in actin filaments, myosin II and various actin-binding proteins [66]. It plays an important role in various cellular processes including cytokinesis, motility, migration, phagocytosis and tissue morphogenesis [66]. The small GTPase Ras homolog gene family member A (RhoA) regulates the contractile cortex assembly [67] and subsequent enhancement in cell polarity and locomotion [68, 69]. RhoA plays an important role in the regulation of actin cortex assembly by inducing actin polymerization and subsequent interaction with myosin. Several proteins of the actin machinery, such as formins (actin-nucleating protein), actin nucleators and associated proteins (CDC42, Arp2/3, DIAPH3, DIP, FMNL1, FHOD1), have been shown to play a critical role in bleb formation in various cells [7]. It is well documented that actin is the main component of most forms of blebs [6, 9, 70-72]. Charras et al. [7] demonstrated the involvement of actin and various actin-binding proteins in the blebbing of filamin-deficient M2 cells. They found that the erythroid submembranous cytoskeleton protein 4.1 and ankyrin- $\beta$ as well as tropomyosin and tropomodulin (which are involved in myosin contraction) were present inside the cytoplasmic compartment of the blebs. Microinjection of a dominant active ezrin (which stabilizes the actin membrane attachment) inhibited bleb formation, suggesting that this phenomenon occurs in areas of weak actinmembrane adhesion. The RhoA-ROCK (Rho-associated protein kinase)-myosin axis plays a central role in the formation of both apoptotic and nonapoptotic membrane blebbing $[8,19,73,74]$. For example, the upregulation of RhoA in the absence of the tumor suppressor genes p53 [73], Rac1 GTPase [75-78] or ROCK [79] can induce plasma membrane blebs. Furthermore, membrane blebbing can be induced in areas of weak cortex-membrane interactions caused by a lack of actin-binding protein filamin A $[9,80]$, the membrane linker protein talin [81] or PIP2 [81, 82].

The contractile activity of myosin, through its phosphorylation by myosin light chain kinase (MLCK), is also important for bleb formation [83, 84]. Microinjection of catalytically active MLCK can induce blebs [85], whilst inhibitors of MLCK and Rho kinase activity, or the actin depolymerizer cytochalasin $\mathrm{D}$, all inhibit bleb formation in serum-deprived Z-VAD-FMK-treated PC6-3 cells [44]. A recent study showed that shRNA-mediated knockdown of the $15-\mathrm{kDa}$ selenoprotein (Sep 15) in the Chang liver cell line, as well as in T-REX-HeLa cells, resulted in cell shrinkage with rounded morphology and the formation of nonapoptotic reversible membrane blebs by remodeling of cytoskeletal proteins such as a-tubulin and F-actin [86]. Pretreatment with inhibitors of ROCK, RhoA, MLCK or blebbistatin reversed bleb morphology within $10 \mathrm{~h}$, suggesting the importance of the ROCK/RhoA/MLCK pathway in membrane blebbing of Sep15-deficient cells.

Besides the well-established role of the actin machinery, various protein kinases such as death-associated protein kinase (DAPK), Src and Met have been shown to be involved in bleb formation.

\section{Death-Associated Protein Kinase}

DAPK is a calcium/calmodulin-regulated, cytoskeleton-associated serine/threonine kinase which enhances cell apoptosis in response to various stimuli [87]. Its overexpression can induce apoptotic blebs in various cell types $[79,88,89]$, which are independent of Rho kinase but dependent on increased myosin contractility $[90,91]$. 
In marked contrast, DAPK can also inhibit membrane blebbing through the regulation of cytoskeletal proteins such as tropomyosin, which plays a role in stress fiber formation and stabilization $[92,93]$.

\section{Proto-Oncogene Tyrosine-Protein Kinase Src}

The Src protein family plays an important role in regulating various intracellular signaling networks [94] and in controlling cell migration, proliferation and survival [95]. The Src homology 4 (SH4) domain plays a key role as an anchoring membrane-targeting domain for Src localization and activation [96, 97]. Interestingly, the expression of the SH4 domains in Leishmania parasite virulence factor HASPB (hydrophilic acylated surface protein B) induced nonapoptotic ROCK-myosin-II-dependent plasma membrane blebs. Endogenous Src activity was crucial for the formation of these blebs in SH4 domainexpressing cells and led to enhanced Src-induced cell invasion [19].

\section{Met Receptor Tyrosine Kinase}

The Met receptor tyrosine kinase/hepatocyte growth factor axis plays a key role in tumor growth and metastasis [98-100]. Constitutively active Met expression induces membrane blebbing in the invasive Moloney sarcoma virus-transformed MDCK MSV-MDCK-INV [101-103], small cell lung cancer cells [104], as well as in breast cancer cell lines MDA-MB-231 and B549 [105]. This can be significantly inhibited by pretreatment with inhibitors of ROCK and actin assembly (latrunculin A and jasplakinolide). In addition, Met-induced blebbing enhances breast cancer cell motility, migration and invasion [105].

\section{Stimuli Inducing Bleb Formation}

Cell blebbing can be manipulated by mechanical or chemical treatment. It can be induced following microtubule disassembly $[42,106,107]$, by inhibition of actin polymerization [7], increasing membrane rigidity or inactivating myosin motors $[8,108]$, and by modulating intracellular pressure $[8,10]$. In addition, blebbing can be induced through alteration in cell adhesion machinery, as seen in MDA-MB-231 breast cancer cells when coated with Matrigel [109], or by detachment of rat liver epithelial cells by the stable expression of a constitutively active
Q63L version of RhoA [110]. In a recent study using the Chinese hamster ovary $\mathrm{CHO}$ fibroblast cell line, it was shown that compression and subsequent dilation (folding and unfolding) of the plasma membrane cortical layers induced cell rounding and migration through membrane blebs [111]. Blebs can also be induced in response to various extracellular stimuli. For example, bleb formation was dependent on the presence of serum components in human conjunctiva cell culture medium [112] and on lysophosphatidic acid in the NB2a rat neuroblastoma cells [113] and zebra fish progenitor cells [18]. In addition, the neurotransmitter cholecystokinin was found to induce blebbing in rat pancreatic acinar cells $[114,115]$, the chemoattractant cAMP (cyclic adenosine monophosphate) in Dictyostelium discoideum cells [5, 43], the chemokine SDE1 $\alpha$ in zebra fish [16], mitoxantrone in HL60 cells [116] and extracellular adenosine triphosphate (ATP) via stimulation of the ATP-gated ion channel P2X7 [117, 118]. The neuropeptide bradykinin (acting through B2 receptors) induced human glioma cell migration through the generation of bleb-like structures, regulated by intracellular calcium, resulting in the contraction of the actin cytoskeleton, cytoplasmic flow and the activation of calcium-dependent $\mathrm{K}^{+}$and $\mathrm{Cl}^{-}$channels [119]. Pretreatment with the myosin II kinase inhibitor, blebbistatin, abolished both bleb formation and motility. These data suggest the occurrence of actin-rich blebs in response to a wide range of stimuli (either mechanical or chemical).

Blebbing has been shown to play an important role in various physiological and pathophysiological conditions. Its role in enhancing cell motility and invasion, immune cell maturation and activation, and pathogenic escape is discussed in the following section. In addition, recent data are presented regarding the role of actin-rich blebs in endocrine-resistant breast cancer cells upon exposure to extracellular alkaline $\mathrm{pH}$.

\section{Role of Blebbing in Cellular Locomotion}

Cell locomotion and polarity play an important role during embryonic development, wound healing and inflammation, and also in cancer metastasis $[13,27,114$, 120]. The latter process involves directional motility/invasion towards a chemoattractant and is associated with one-sided formation of protrusions such as lamellipodia (which are flattened), microspikes (or filopodia), which are narrow and stiff rods, or blebs (also called lobopodia) [120]. Most of these actin-rich protrusions are formed 
preferentially at the leading edge of the crawling cells to guide them towards a site of inflammation or infection (in the case of immune cells), or to effectively enhance penetration of cancer cells into blood or lymphatic vessels. Cellular protrusions are of two main types: those driven by actin polymerization such as pseudopodia or lamellipodia, and those driven by fluid pressure such as blebs. In addition to enabling tumor invasion [121], as seen for M2 melanoma and Walker carcinoma cells $[51,80]$ and breast cancer cells [105], blebbing is involved in the migration of primordial germ cells of zebra fish $[16,17]$, the pathogen Entamoeba histolytica into the liver [122], Dictyostelium ameba under 2\% agarose [43], Leishmania parasite [19], HEK-293 cells [65], Drosophila [123], Xenopus laevis [124] and killifish deep cells [125]. Actinomycin-rich membrane blebs are also evident in the sea urchin red spherule coelomocyte immune cells, which enhance their motility. Treatment with cytochalasin B or blebbistatin can abolish membrane blebbing and cell motility, highlighting the importance of these protrusions in immune cell motility [12]. Various reports have shown the coexistence of blebs and F-actin-driven protrusions at the leading edge of migrating cells $[11,45]$, and blebs can give rise to pseudopods or vice versa by continued actin polymerization.

Motile cells have a variety of shapes and move at differing speeds in different environments, generally extending their outer edges by actin polymerization for forward movement [120, 126-128]. Yoshida and Soldati [43] showed Dictyostelium cells utilizing mainly actin-driven pseudopods as well as small transient blebs, whilst another study suggested that their motility was purely bleb driven, evoked by mechanical resistance, dependent on PI3K activity and strongly chemotactic [45]. Cancer cells may switch between F-actin-driven to bleb-driven motility according to their environment [74, 121]. For example, when cancer cells experience genetic impairment of F-actin polymerization, they compensate by using unbranched actin filaments or blebs for locomotion [129, 130]. Furthermore, some reports have demonstrated that cancer cells could invade the extracellular matrix (ECM) through various mechanisms including mesenchymalproteolytic degradation of ECM on a flat surface and ameboid blebbing motility in collagen gels [121] squeezing between the pores in the ECM and invading in a manner independent of proteolytic activity $[74,131,132] . E$. histolytica cells, the causative agents of amebiasis [133], utilize ameboid bleb-driven motility to enable them to invade various organs such as liver parenchyma [122]. E. histolytica motility using blebs is approximately two or- ders of magnitude faster than the average motion of mesenchymal cells. As with cancer cells, these data suggest that E. histolytica can be prompted to switch between bleb-driven and mesenchymal motility depending on the environment. Interestingly, noninvasive cells can be transformed into an invasive phenotype by the experimental induction of membrane blebs $[19,73]$. Sharma et al. [134] demonstrated that glioma cells produce continuous actin-rich blebs when cultured on a flat surface, while exhibiting reversible blebbing and nonblebbing phenomenon on suspended STEP (spinneret-based tunable engineered parameters) fibrous substrates. They also observed that blebs on a single cell were greater in number and longer in size when cells were in smaller and spherical morphologies. Bleb formation was significantly reduced when glioma cells were spread along the STEP nanofibers. An inverse relationship was observed between blebbing and cell migration, in contrast to previous reports using other stimuli to induce membrane blebbing. It should be noted that treatment with various growth factors, such as fibroblast growth factor, platelet-derived growth factor or epithelial growth factor, did not induce membrane blebbing in zebra fish progenitor cells [18], which is consistent with our own observations in ERsilenced endocrine-resistant breast cancer cells [11].

These data highlight the importance of blebbing in enhancing cell motility through several mechanisms. The blebs appear to induce movement through the formation of circular projections emanating from the plasma membrane. Live cell imagery of cultured cells shows a circular movement of the blebs around the cell periphery [9]. When confronted with a chemoattractant, the blebs polarize along the part of the cell facing the stimuli and thereby allow cytoplasmic streaming which propels the cell in one direction. Furthermore, actin-rich blebs could provide driving forces to enable the cell to move forward, and also allow the cell to move in a 'swimming fashion' due to asymmetric cell shape changes during bleb formation, particularly in a $3 \mathrm{D}$ environment. Blebs could provide an alternative (backup) means for cellular motility when other cellular projections are impaired or deficient.

Besides their role in cell locomotion, recent data suggest their involvement in modulating the activity of the immune system as well as in cancer pathogenesis $[11,27$, 135].

\section{Blebbing: A Vaccine-Based Therapy}

During apoptosis, the endoplasmic reticulum, RNA and chromatin are enclosed within blebs, which become detached from the main apoptotic cell at the later stages
Khajah/Luqmani 
$[136,137]$. This phenomenon was suggested to aid immune maturation and the formation of vaccines to enable the killing of tumor cells. It was shown that ingestion of blebs by mouse-derived dendritic cells induced their maturation and subsequent Th17 cell activation when co-cultured with splenocytes in vitro [138, 139], as well as in mice in vivo [140]. Ruben et al. [116] showed that blebs were generated from mitoxantrone-treated apoptotic HL60 cells (the human HLA-A2-negative AML cell line), which contain chromatin and endoplasmic reticulum. In addition, the apoptotic blebs were ingested by monocytederived dendritic cells (at $48 \mathrm{~h}$ co-culture), leading to increased expression of the lymph node homing receptor CCR7, enhanced migration towards CCL19, increased IFN $\gamma$ production and $\mathrm{CD} 4^{+} \mathrm{T}$-cell proliferation, with higher avidity of T cells towards HL60 AML cells. It is tempting to speculate that apoptotic blebs from AML cells may serve as a source of tumor-associated antigen for dendritic cell-based vaccine therapy.

\section{Blebbing: Recruiting Immune Cells}

Spontaneous apoptosis of tonsil-derived human germinal center B cells results in the loss of various cell adhesion molecules and the formation of multiple blebs on the outer cell membrane [135]. It has been shown that blebs derived from apoptotic germinal center B cells (but not from $T$ cells) exhibited chemotactic activity towards peripheral blood monocytes. This process might play a role in vivo in recruiting the monocytes (professional phagocytes) to eliminate apoptotic B cells and prevent inflammatory reactions.

\section{Blebbing: Escaping the Immune System}

The opportunistic pathogen Pseudomonas aeruginosa targets surface-exposed epithelial cells and can infect any part of the human body [141]. It can infect cultured epithelial cells in vitro by entering through cells which display plasma membrane blebs to allow it to be isolated from the cytoplasm and to swim rapidly within them [21, $22,142]$. This phenomenon has also been shown in vivo in corneal epithelial cells within excised whole mouse eyes [143]. Recent evidence suggests that $P$. aeruginosainduced apoptotic epithelial cell blebbing is independent of actin contraction but dependent on the ExoS type 3 secretion system effector [22, 142] and cystic fibrosis transmembrane regulator osmoregulatory function [20].

\section{Blebbing: Disease-Causing Protrusions}

Suprastimulation of pancreatic acinar cells with the cholecystokinin octapeptide results in marked basolater- al membrane blebbing and ameboid shape within $2 \mathrm{~min}$ of the stimulation [144-146]. This can be quickly reversed by reducing the concentration of the stimuli. The actin machinery has been postulated to play a role in cholecystokinin-mediated blebbing of pancreatic acinar cells, accompanied by marked reorganization of cytoplasmic actin and phosphorylation of myosin II. In addition, pretreatment with the actin depolymerizer cytochalasin D, the myosin ATPase inhibitor butanedione monoxime and the MLCK inhibitor ML-9 all inhibited bleb formation. The blebs in the acinar cells were shown to be responsible for the development of acute interstitial pancreatitis in animals [147].

\section{Blebbing in Endocrine-Resistant Breast Cancer Cells}

It has recently been shown that a brief (5-min) exposure of specifically endocrine-resistant breast cancer cells to an extracellular alkaline (but not acidic) pH environment induces cell rounding and shrinkage, and the formation of actin-rich membrane blebs on the outer membrane of the cells $[11,27]$. Various molecules that are critical for cell motility and invasion, such as integrin $\alpha 2$, JAM-1 (junctional adhesion molecule-1) and FAK (focal adhesion kinase), are translocated into the cytoplasmic compartment of the newly formed blebs. Other molecules that are not important for motility, such as vimentin, do not show any cytoplasmic redistribution upon exposure to alkaline $\mathrm{pH}$. Pretreatment with cytochalasin D, MLCK and Rho kinase inhibitors, as well as inhibitors of $\mathrm{Na}^{+} / \mathrm{H}^{+}$ and $\mathrm{Na}^{+/} \mathrm{K}^{+}$channels, completely inhibits cellular blebbing. The blebs are highly dynamic, polarizing in the direction of a chemoattractant, in this case epithelial growth factor, and significantly enhancing cell invasiveness, whereas they exhibited a uniform distribution profile when exposed to a source containing the vehicle only. This phenomenon is completely reversible by returning the cells to physiological $\mathrm{pH}(\mathrm{pH} 7.4)$, although prolonged exposure (beyond $4 \mathrm{~h}$ ) induces apoptosis (evident by increased levels of various heat shock proteins). These observations are the first indication that alkaline $\mathrm{pH}$ can induce bleb formation and that both apoptotic and nonapoptotic blebs can form in the same cell depending on the length of exposure. Both actin and MLCK were implicated in the formation of these blebs, which is in agreement with previous reports. The loss of the epithelial marker E-cadherin may play a role in the formation of alkaline-induced blebbing in the ER-ve breast cancer cells which have undergone epithelial to mesenchymal transi- 
tion. This results in weaker cell-cell contact and the cell will acquire the flexibility to modify its morphology in response to a high extracellular $\mathrm{pH}$ environment. Furthermore, the cytoplasmic compartment of the newly formed blebs differs from the cytoplasm in the rest of the cell as it concentrates molecules critical for cell motility and invasion. We have also generated preliminary data suggesting the involvement of secreted components from the formed blebs which aid in enhanced cell invasion. Conditioned medium from cells exposed to alkaline $\mathrm{pH}$ enhances the invasion of cells cultured at $\mathrm{pH}$ 7.4.

\section{Conclusions}

Membrane blebbing has been observed in many cell types through the activation of various signaling molecules downstream of a broad range of external mechanical and chemical stimuli. The nonapoptotic form of membrane blebs plays an important role in various cellular functions, particularly motility. Recent evidence suggests their potential usefulness in vaccine-based therapy or as possible therapeutic targets in the treatment of interstitial pancreatitis. In the case of cancer cells, these exhibit this phenomenon in order to form protrusions, which compensate in case of deformities in the F-actin machinery, to enable them to invade into the ECM and beyond or to allow them to escape from unusual hostile extracellular environments (such as exposure to alkaline $\mathrm{pH}$ ). Targeting membrane blebs with antiblebbing agents in conjunction with anti-inflammatory or antimetastatic agents might serve as a novel treatment approach to reduce cancer cell motility and metastasis. The various stimuli and molecules involved in membrane blebbing, as well as multiple cellular functions modulated by these protrusions, are summarized in the schema illustrated in figure 1.

\section{Disclosure Statement}

The authors declare that no conflicts of interest exist.

\section{References}

1 Hogue MJ: The effect of hypotonic and hypertonic solutions on fibroblasts of the embryonic chick heart in vitro. J Exp Med 1919;30: 617-648.

2 Charras GT: A short history of blebbing. J Microsc 2008;231:466-478.

3 Norman LL, Brugues J, Sengupta K, et al: Cell blebbing and membrane area homeostasis in spreading and retracting cells. Biophys J 2010; 99:1726-1733.

4 Norman L, Sengupta K, Aranda-Espinoza H: Blebbing dynamics during endothelial cell spreading. Eur J Cell Biol 2011;90:37-48.

5 Langridge PD, Kay RR: Blebbing of Dictyostelium cells in response to chemoattractant. Exp Cell Res 2006;312:2009-2017.

6 Laster SM, Mackenzie JM Jr: Bleb formation and $\mathrm{F}$-actin distribution during mitosis and tumor necrosis factor-induced apoptosis. Microsc Res Tech 1996;34:272-280.

7 Charras GT, Hu CK, Coughlin M, et al: Reassembly of contractile actin cortex in cell blebs. J Cell Biol 2006;175:477-490.

8 Charras GT, Yarrow JC, Horton MA, et al: Non-equilibration of hydrostatic pressure in blebbing cells. Nature 2005;435:365-369.

9 Cunningham CC: Actin polymerization and intracellular solvent flow in cell surface blebbing. J Cell Biol 1995;129:1589-1599.

10 Dai J, Sheetz MP: Membrane tether formation from blebbing cells. Biophys J 1999; 77:33633370.
11 Khajah MA, Mathew PM, Alam-Eldin NS, et al: Bleb formation is induced by alkaline but not acidic $\mathrm{pH}$ in estrogen receptor silenced breast cancer cells. Int J Oncol 2015;46:16851698.

12 D'Andrea-Winslow L, Novitski AK: Active bleb formation is abated in Lytechinus variegatus red spherule coelomocytes after disruption of acto-myosin contractility. Integr Zool 2008;3:115-122.

13 Loitto VM, Forslund T, Sundqvist T, et al: Neutrophil leukocyte motility requires directed water influx. J Leukoc Biol 2002;71:212222.

14 Grinnell F: Migration of human neutrophils in hydrated collagen lattices. J Cell Sci 1982; 58:95-108.

15 Dzementsei A, Schneider D, Janshoff A, et al: Migratory and adhesive properties of Xenopus laevis primordial germ cells in vitro. Biol Open 2013;2:1279-1287.

16 Blaser H, Reichman-Fried M, Castanon I, et al: Migration of zebrafish primordial germ cells: a role for myosin contraction and cytoplasmic flow. Dev Cell 2006;11:613-627.

17 Row RH, Maitre JL, Martin BL, et al: Completion of the epithelial to mesenchymal transition in zebrafish mesoderm requires Spadetail. Dev Biol 2011;354:102-110.

18 Ruprecht V, Wieser S, Callan-Jones A, et al: Cortical contractility triggers a stochastic switch to fast amoeboid cell motility. Cell 2015;160:673-685.
19 Tournaviti S, Hannemann S, Terjung S, et al: SH4-domain-induced plasma membrane dynamization promotes bleb-associated cell motility. J Cell Sci 2007;120:3820-3829.

20 Jolly AL, Takawira D, Oke OO, et al: Pseudomonas aeruginosa-induced bleb-niche formation in epithelial cells is independent of actinomyosin contraction and enhanced by loss of cystic fibrosis transmembrane-conductance regulator osmoregulatory function. MBio 2015;6:e02533.

21 Heimer SR, Evans DJ, Stern ME, et al: Pseudomonas aeruginosa utilizes the type III secreted toxin ExoS to avoid acidified compartments within epithelial cells. PLoS One 2013;8:e73111.

22 Angus AA, Lee AA, Augustin DK, et al: Pseudomonas aeruginosa induces membrane blebs in epithelial cells, which are utilized as a niche for intracellular replication and motility. Infect Immun 2008;76:1992-2001.

23 VanWinkle WB, Snuggs M, Miller JC, et al: Cytoskeletal alterations in cultured cardiomyocytes following exposure to the lipid peroxidation product, 4-hydroxynonenal. Cell Motil Cytoskeleton 1994;28:119-134.

24 Friedman JE, Haddad GG: Major differences in $\mathrm{Ca}^{2+}{ }_{i}$ response to anoxia between neonatal and adult rat CA1 neurons: Role of $\mathrm{Ca}^{2+}{ }_{\mathrm{o}}$ and $\mathrm{Na}^{+}{ }_{0}$. J Neurosci 1993;13:63-72.

25 Johnson ME, Gores GJ, Uhl CB, et al: Cytosolic free calcium and cell death during metabolic inhibition in a neuronal cell line. J Neurosci 1994;14:4040-4049. 
26 Marcussen M: Induction of cell surface blebbing by increased cellular Pi concentration. Biochem J 1996;318:955-958.

27 Khajah MA, Almohri I, Mathew PM, et al: Extracellular alkaline $\mathrm{pH}$ leads to increased metastatic potential of estrogen receptor silenced endocrine resistant breast cancer cells. PLoS One 2013;8:2013.

28 Gong J, Jaiswal R, Mathys JM, et al: Microparticles and their emerging role in cancer multidrug resistance. Cancer Treat Rev 2012;38: 226-234.

29 Trinkaus JP: Surface activity and locomotion of Fundulus deep cells during blastula and gastrula stages. Dev Biol 1973;30:69-103.

30 Fackler OT, Grosse R: Cell motility through plasma membrane blebbing. J Cell Biol 2008; 181:879-884.

31 Charras G, Paluch E: Blebs lead the way: how to migrate without lamellipodia. Nat Rev Mol Cell Biol 2008;9:730-736.

32 Babiychuk EB, Monastyrskaya K, Potez S, et al: Blebbing confers resistance against cell lysis. Cell Death Differ 2011;18:80-89.

33 Kerr JF, Wyllie AH, Currie AR: Apoptosis: a basic biological phenomenon with wideranging implications in tissue kinetics. $\mathrm{Br} \mathrm{J}$ Cancer 1972;26:239-257.

34 Chen J, Dai J, Grant RL, et al: Loss of cytoskeletal support is not sufficient for anoxic plasma membrane disruption in renal cells. Am J Physiol 1997;272:C1319-C1328.

35 Wang YL: Exchange of actin subunits at the leading edge of living fibroblasts: possible role of treadmilling. J Cell Biol 1985;101:597-602.

36 Theriot JA, Mitchison TJ: Actin microfilament dynamics in locomoting cells. Nature 1991;352:126-131.

37 Sheetz MP, Wayne DB, Pearlman AL: Extension of filopodia by motor-dependent actin assembly. Cell Motil Cytoskeleton 1992;22: 160-169.

38 Boucrot E, Kirchhausen T: Endosomal recycling controls plasma membrane area during mitosis. Proc Natl Acad Sci USA 2007;104: 7939-7944.

39 Bereiter-Hahn J, Luck M, Miebach T, et al: Spreading of trypsinized cells: cytoskeletal dynamics and energy requirements. J Cell Sci 1990;96:171-188.

40 Erickson CA, Trinkaus JP: Microvilli and blebs as sources of reserve surface membrane during cell spreading. Exp Cell Res 1976;99: 375-384.

41 Hoglund AS: The arrangement of microfilaments and microtubules in the periphery of spreading fibroblasts and glial cells. Tissue Cell 1985;17:649-666.

42 Keller H, Eggli P: Protrusive activity, cytoplasmic compartmentalization, and restriction rings in locomoting blebbing walker carcinosarcoma cells are related to detachment of cortical actin from the plasma membrane. Cell Motil Cytoskeleton 1998;41:181-193.

43 Yoshida K, Soldati T: Dissection of amoeboid movement into two mechanically distinct modes. J Cell Sci 2006;119:3833-3844.
44 Mills JC, Stone NL, Erhardt J, et al: Apoptotic membrane blebbing is regulated by myosin light chain phosphorylation. J Cell Biol 1998; 140:627-636.

45 Zatulovskiy E, Tyson R, Bretschneider T, et al: Bleb-driven chemotaxis of Dictyostelium cells. J Cell Biol 2014;204:1027-1044.

46 Skoufias DA, DeBonis S, Saoudi Y, et al: Strityl-L-cysteine is a reversible, tight binding inhibitor of the human kinesin Eg5 that specifically blocks mitotic progression. J Biol Chem 2006;281:17559-17569.

47 Cooper JA: The role of actin polymerization in cell motility. Annu Rev Physiol 1991;53: 585-605.

48 Peskin CS, Odell GM, Oster GF: Cellular motions and thermal fluctuations: the Brownian ratchet. Biophys J 1993;65:316-324.

49 Cramer LP, Mitchison TJ, Theriot JA: Actindependent motile forces and cell motility. Curr Opin Cell Biol 1994;6:82-86.

50 Bereiter-Hahn J, Strohmeier R, Kunzenbacher I, et al: Locomotion of Xenopus epidermis cells in primary culture. J Cell Sci 1981;52: 289-311.

51 Keller HU, Bebie H: Protrusive activity quantitatively determines the rate and direction of cell locomotion. Cell Motil Cytoskeleton 1996;33:241-251.

52 Oster G: Biophysics of the leading lamella. Cell Motil Cytoskeleton 1988;10:164-171.

53 Bretscher MS: Endocytosis and recycling of the fibronectin receptor in $\mathrm{CHO}$ cells. EMBO J 1989;8:1341-1348.

54 Carter SB: Principles of cell motility: the direction of cell movement and cancer invasion. Nature 1965;208:1183-1187.

55 Dong C, Aznavoorian S, Liotta LA: Two phases of pseudopod protrusion in tumor cells revealed by a micropipette. Microvasc Res 1994; 47:55-67.

56 Strohmeier R, Bereiter-Hahn J: Hydrostatic pressure in epidermal cells is dependent on Ca-mediated contractions. J Cell Sci 1987;88: 631-640.

57 Fedier A, Keller HU: Suppression of bleb formation, locomotion, and polarity of Walker carcinosarcoma cells by hypertonic media correlates with cell volume reduction but not with changes in the F-actin content. Cell Motil Cytoskeleton 1997;37:326-337.

58 Rassokhin MA, Pakhomov AG: Electric field exposure triggers and guides formation of pseudopod-like blebs in U937 monocytes. J Membr Biol 2012;245:521-529.

59 Preston GM, Carroll TP, Guggino WB, et al: Appearance of water channels in Xenopus oocytes expressing red cell CHIP28 protein. Science 1992;256:385-387.

60 Agre P, Smith BL, Baumgarten R, et al: $\mathrm{Hu}-$ man red cell Aquaporin CHIP. II. Expression during normal fetal development and in a novel form of congenital dyserythropoietic anemia. J Clin Invest 1994;94:1050-1058.

61 Gonen T, Walz T: The structure of aquaporins. Q Rev Biophys 2006;39:361-396.
62 Papadopoulos MC, Saadoun S, Verkman AS: Aquaporins and cell migration. Pflugers Arch 2008;456:693-700.

63 Saadoun S, Papadopoulos MC, Hara-Chikuma $\mathrm{M}$, et al: Impairment of angiogenesis and cell migration by targeted aquaporin-1 gene disruption. Nature 2005;434:786-792.

64 Loitto VM, Karlsson T, Magnusson KE: Water flux in cell motility: expanding the mechanisms of membrane protrusion. Cell Motil Cytoskeleton 2009;66:237-247.

65 Karlsson T, Bolshakova A, Magalhaes MA, et al: Fluxes of water through aquaporin 9 weaken membrane-cytoskeleton anchorage and promote formation of membrane protrusions. PLoS One 2013;8:3.

66 Bray D, White JG: Cortical flow in animal cells. Science 1988;239:883-888.

67 Etienne-Manneville S, Hall A: Rho GTPases in cell biology. Nature 2002;420:629-635.

68 Lee JH, Katakai T, Hara T, et al: Roles of p-ERM and Rho-ROCK signaling in lymphocyte polarity and uropod formation. J Cell Biol 2004;167:327-337.

69 Kamijo K, Ohara N, Abe M, et al: Dissecting the role of Rho-mediated signaling in contractile ring formation. Mol Biol Cell 2006;17:43-55.

70 Cotter TG, Lennon SV, Glynn JM, et al: Microfilament-disrupting agents prevent the formation of apoptotic bodies in tumor cells undergoing apoptosis. Cancer Res 1992;52: 997-1005.

71 Pitzer F, Dantes A, Fuchs T, et al: Removal of proteasomes from the nucleus and their accumulation in apoptotic blebs during programmed cell death. FEBS Lett 1996;394:4750.

72 Vemuri GS, Zhang J, Huang R, et al: Thrombin stimulates wortmannin-inhibitable phosphoinositide 3-kinase and membrane blebbing in CHRF-288 cells. Biochem J 1996;314: 805-810.

73 Gadea G, de Toledo M, Anguille C, et al: Loss of p53 promotes RhoA-ROCK-dependent cell migration and invasion in 3D matrices. J Cell Biol 2007;178:23-30.

74 Sahai E, Marshall CJ: Differing modes of tumour cell invasion have distinct requirements for Rho/ROCK signalling and extracellular proteolysis. Nat Cell Biol 2003;5:711-719.

75 Sander EE, ten Klooster JP, van Delft S, et al: Rac downregulates Rho activity: reciprocal balance between both GTPases determines cellular morphology and migratory behavior. J Cell Biol 1999;147:1009-1022.

76 Ohta Y, Hartwig JH, Stossel TP: FilGAP, a Rho- and ROCK-regulated GAP for Rac binds filamin A to control actin remodelling. Nat Cell Biol 2006;8:803-814.

77 Schwartz MA, Meredith JE, Kiosses WB: An activated Rac mutant functions as a dominant negative for membrane ruffling. Oncogene 1998; 17:625-629.

78 Lee E, Seastone DJ, Harris E, et al: RacB regulates cytoskeletal function in Dictyostelium spp. Eukaryot Cell 2003;2:474-485. 
79 Shani G, Marash L, Gozuacik D, et al: Deathassociated protein kinase phosphorylates ZIP kinase, forming a unique kinase hierarchy to activate its cell death functions. Mol Cell Biol 2004;24:8611-8626.

80 Cunningham CC, Gorlin JB, Kwiatkowski DJ, et al: Actin-binding protein requirement for cortical stability and efficient locomotion. Science 1992;255:325-327.

81 Wang Y, Litvinov RI, Chen X, et al: Loss of PIP5KI $\gamma$, unlike other PIP5KI isoforms, impairs the integrity of the membrane cytoskeleton in murine megakaryocytes. J Clin Invest 2008;118:812-819.

82 Raucher D, Stauffer T, Chen W, et al: Phosphatidylinositol 4,5-bisphosphate functions as a second messenger that regulates cytoskeleton-plasma membrane adhesion. Cell 2000; 100:221-228.

83 Kohama K, Ye LH, Hayakawa K, et al: Myosin light chain kinase: an actin-binding protein that regulates an ATP-dependent interaction with myosin. Trends Pharmacol Sci 1996;17: 284-287.

84 Gallagher PJ, Herring BP, Stull JT: Myosin light chain kinases. J Muscle Res Cell Motil 1997;18:1-16.

85 Fishkind DJ, Cao LG, Wang YL: Microinjection of the catalytic fragment of myosin light chain kinase into dividing cells: effects on mitosis and cytokinesis. J Cell Biol 1991;114: 967-975.

86 Bang J, Jang M, Huh JH, et al: Deficiency of the $15-\mathrm{kDa}$ selenoprotein led to cytoskeleton remodeling and non-apoptotic membrane blebbing through a RhoA/ROCK pathway. Biochem Biophys Res Commun 2015;456: 884-890.

87 Bialik S, Kimchi A: The death-associated protein kinases: structure, function, and beyond. Annu Rev Biochem 2006;75:189-210.

88 Cohen O, Feinstein E, Kimchi A: Dap-kinase is a $\mathrm{Ca}^{2+} /$ calmodulin-dependent, cytoskeletal-associated protein kinase, with cell deathinducing functions that depend on its catalytic activity. EMBO J 1997;16:998-1008.

89 Cohen O, Inbal B, Kissil JL, et al: DAP-kinase participates in TNF- $\alpha$ - and Fas-induced apoptosis and its function requires the death domain. J Cell Biol 1999;146:141-148.

90 Bialik S, Bresnick AR, Kimchi A: DAP-kinase-mediated morphological changes are localization dependent and involve myosin-II phosphorylation. Cell Death Differ 2004;11: 631-644.

91 Kuo JC, Lin JR, Staddon JM, et al: Uncoordinated regulation of stress fibers and focal adhesions by DAP kinase. J Cell Sci 2003;116: 4777-4790.

92 Cooper JA: Actin dynamics: tropomyosin provides stability. Curr Biol 2002;12:R523R525.

93 Houle F, Poirier A, Dumaresq J, et al: Dap kinase mediates the phosphorylation of tropomyosin-1 downstream of the ERK pathway, which regulates the formation of stress fibers in response to oxidative stress. J Cell Sci 2007; 120:3666-3677.

94 Thomas SM, Brugge JS: Cellular functions regulated by Src family kinases. Annu Rev Cell Dev Biol 1997;13:513-609.

95 Frame MC: Newest findings on the oldest oncogene; how activated Src does it. J Cell Sci 2004;117:989-998.

96 Kaplan JM, Mardon G, Bishop JM, et al: The first seven amino acids encoded by the v-Src oncogene act as a myristylation signal: lysine 7 is a critical determinant. Mol Cell Biol 1988; 8:2435-2441.

97 Sigal CT, Zhou W, Buser CA, et al: Aminoterminal basic residues of $\mathrm{Src}$ mediate membrane binding through electrostatic interaction with acidic phospholipids. Proc Natl Acad Sci USA 1994;91:12253-12257.

98 Bottaro DP, Rubin JS, Faletto DL, et al: Identification of the hepatocyte growth factor receptor as the C-Met proto-oncogene product. Science 1991;251:802-804.

99 Zeng Q, Chen S, You Z, et al: Hepatocyte growth factor inhibits anoikis in head and neck squamous cell carcinoma cells by activation of ERK and Akt signaling independent of NF-кB. J Biol Chem 2002;277: 25203-25208.

100 Gherardi E, Birchmeier W, Birchmeier C, et al: Targeting Met in cancer: rationale and progress. Nat Rev Cancer 2012;12:89-103.

101 Nguyen TN, Wang HJ, Zalzal S, et al: Purification and characterization of $\beta$-actin-rich tumor cell pseudopodia: role of glycolysis. Exp Cell Res 2000;258:171-183.

102 Vadnais J, Nault G, Daher Z, et al: Autocrine activation of the hepatocyte growth factor receptor/Met tyrosine kinase induces tumor cell motility by regulating pseudopodial protrusion. J Biol Chem 2002;277:48342-48350.

103 Jia Z, Vadnais J, Lu ML, et al: Rho/ROCKdependent pseudopodial protrusion and cellular blebbing are regulated by $\mathrm{p} 38 \mathrm{MAPK}$ in tumour cells exhibiting autocrine C-Met activation. Biol Cell 2006;98:337-351.

104 Maulik G, Kijima T, Ma PC, et al: Modulation of the C-Met/hepatocyte growth factor pathway in small cell lung cancer. Clin Cancer Res 2002;8:620-627.

105 Laser-Azogui A, Diamant-Levi T, Israeli S, et al: Met-induced membrane blebbing leads to amoeboid cell motility and invasion. Oncogene 2014;33:1788-1798.

106 Cuvelier D, Thery M, Chu YS, et al: The universal dynamics of cell spreading. Curr Biol 2007;17:694-699.

107 Keller H, Rentsch P, Hagmann J: Differences in cortical actin structure and dynamics document that different types of blebs are formed by distinct mechanisms. Exp Cell Res 2002;277:161-172.

108 Cheung A, Dantzig JA, Hollingworth S, et al: A small-molecule inhibitor of skeletal muscle myosin II. Nat Cell Biol 2002;4:83-88.

109 Kitzing TM, Sahadevan AS, Brandt DT, et al: Positive feedback between Dia1, LARG, and
RhoA regulates cell morphology and invasion. Genes Dev 2007;21:1478-1483.

110 Vasiliev JM, Omelchenko T, Gelfand IM, et al: Rho overexpression leads to mitosis-associated detachment of cells from epithelial sheets: a link to the mechanism of cancer dissemination. Proc Natl Acad Sci USA 2004; 101:12526-12530.

111 Kapustina M, Elston TC, Jacobson K: Compression and dilation of the membranecortex layer generates rapid changes in cell shape. J Cell Biol 2013;200:95-108.

112 Taylor AC: Attachment and spreading of cells in culture. Exp Cell Res 1961;8:154173.

113 Hagmann J, Burger MM, Dagan D: Regulation of plasma membrane blebbing by the cytoskeleton. J Cell Biochem 1999;73:488499.

114 Torgerson RR, McNiven MA: The actinmyosin cytoskeleton mediates reversible agonist-induced membrane blebbing. J Cell Sci 1998;111:2911-2922.

115 Singh VP, McNiven MA: Src-mediated cortactin phosphorylation regulates actin localization and injurious blebbing in acinar cells. Mol Biol Cell 2008;19:2339-2347.

116 Ruben JM, van den Ancker W, Bontkes HJ, et al: Apoptotic blebs from leukemic cells as a preferred source of tumor-associated antigen for dendritic cell-based vaccines. Cancer Immunol Immunother 2014;63:335-345.

117 MacKenzie A, Wilson HL, Kiss-Toth E, et al: Rapid secretion of interleukin- $1 \beta$ by microvesicle shedding. Immunity 2001;15: 825-835.

118 Verhoef PA, Estacion M, Schilling W, et al: P2X7 receptor-dependent blebbing and the activation of Rho-effector kinases, caspases, and IL-1 $\beta$ release. J Immunol 2003;170: 5728-5738.

119 Seifert S, Sontheimer H: Bradykinin enhances invasion of malignant glioma into the brain parenchyma by inducing cells to undergo amoeboid migration. J Physiol 2014; 592:5109-5127.

120 Pollard TD, Borisy GG: Cellular motility driven by assembly and disassembly of actin filaments. Cell 2003;112:453-465.

121 Wolf K, Mazo I, Leung H, et al: Compensation mechanism in tumor cell migration: mesenchymal-amoeboid transition after blocking of pericellular proteolysis. J Cell Biol 2003; 160:267-277.

122 Maugis B, Brugues J, Nassoy P, et al: Dynamic instability of the intracellular pressure drives bleb-based motility. J Cell Sci 2010; 123:3884-3892.

123 Jaglarz MK, Howard KR: The active migration of Drosophila primordial germ cells. Development 1995;121:3495-3503.

124 Wylie CC, Heasman J: The formation of the gonadal ridge in Xenopus laevis. I. A light and transmission electron microscope study. J Embryol Exp Morphol 1976;35:125138. 
125 Fink RD, Trinkaus JP: Fundulus deep cells: directional migration in response to epithelial wounding. Dev Biol 1988;129:179-190.

126 Insall RH, Machesky LM: Actin dynamics at the leading edge: from simple machinery to complex networks. Dev Cell 2009;17:310322.

127 Lammermann T, Sixt M: Mechanical modes of 'amoeboid' cell migration. Curr Opin Cell Biol 2009;21:636-644.

128 Svitkina TM, Borisy GG: Arp2/3 complex and actin depolymerizing factor/cofilin in dendritic organization and treadmilling of actin filament array in lamellipodia. J Cell Biol 1999;145:1009-1026.

129 Suraneni P, Rubinstein B, Unruh JR, et al: The Arp $2 / 3$ complex is required for lamellipodia extension and directional fibroblast cell migration. J Cell Biol 2012;197:239-251.

130 Derivery E, Fink J, Martin D, et al: Free Brick1 is a trimeric precursor in the assembly of a functional wave complex. PLoS One 2008:3:2462

131 Friedl P, Wolf K: Tumour-cell invasion and migration: diversity and escape mechanisms. Nat Rev Cancer 2003;3:362-374.

132 Pathak A, Kumar S: Biophysical regulation of tumor cell invasion: moving beyond matrix stiffness. Integr Biol 2011;3:267-278.

133 Stanley SL Jr: Amoebiasis. Lancet 2003;361: 1025-1034
134 Sharma P, Sheets K, Elankumaran S, et al: The mechanistic influence of aligned nanofibers on cell shape, migration and blebbing dynamics of glioma cells. Integr Biol 2013;5: 1036-1044.

135 Segundo C, Medina F, Rodriguez C, et al: Surface molecule loss and bleb formation by human germinal center B cells undergoing apoptosis: role of apoptotic blebs in monocyte chemotaxis. Blood 1999;94:1012-1020.

136 Lane JD, Allan VJ, Woodman PG: Active relocation of chromatin and endoplasmic reticulum into blebs in late apoptotic cells. J Cell Sci 2005;118:4059-4071.

137 Fransen JH, Hilbrands LB, Ruben J, et al: Mouse dendritic cells matured by ingestion of apoptotic blebs induce $\mathrm{T}$ cells to produce interleukin-17. Arthritis Rheum 2009;60: 2304-2313.

138 Fischer E, Kobold S, Kleber S, et al: Cryptic epitopes induce high-titer humoral immune response in patients with cancer. J Immunol 2010;185:3095-3102.

139 Fransen JH, Hilbrands LB, Jacobs CW, et al: Both early and late apoptotic blebs are taken up by DC and induce IL- 6 production. Autoimmunity 2009;42:325-327.

140 Verdijk P, Aarntzen EH, Lesterhuis WJ, et al: Limited amounts of dendritic cells migrate into the T-cell area of lymph nodes but have high immune activating potential in melanoma patients. Clin Cancer Res 2009;15: 2531-2540.
141 Ratjen F, Doring G: Cystic fibrosis. Lancet 2003;361:681-689.

142 Angus AA, Evans DJ, Barbieri JT, et al: The ADP-ribosylation domain of Pseudomonas aeruginosa ExoS is required for membrane bleb niche formation and bacterial survival within epithelial cells. Infect Immun 2010; 78:4500-4510.

143 Tam C, LeDue J, Mun JJ, et al: 3D quantitative imaging of unprocessed live tissue reveals epithelial defense against bacterial adhesion and subsequent traversal requires MyD88. PLoS One 2011;6:25.

144 Adler G, Kern HF, Pan GZ, et al: Secretagogue-induced membrane alterations in dispersed acini from rat pancreas. Eur J Cell Biol 1984;33:234-241.

145 Burnham DB, Williams JA: Effects of high concentrations of secretagogues on the morphology and secretory activity of the pancreas: a role for microfilaments. Cell Tissue Res 1982;222:201-212.

146 O'Konski MS, Pandol SJ: Effects of caerulein on the apical cytoskeleton of the pancreatic acinar cell. J Clin Invest 1990;86:1649-1657.

147 Lampel M, Kern HF: Acute interstitial pancreatitis in the rat induced by excessive doses of a pancreatic secretagogue. Virchows Arch A Pathol Anat Histol 1977;373:97-117. 